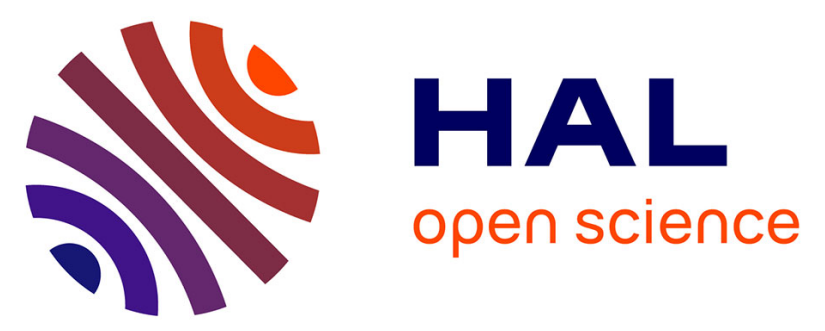

\title{
Reduction in hormone replacement therapy use and declining breast cancer incidence in the Belgian province of Limburg
}

\author{
Patrik Vankrunkelsven, Eliane Kellen, Daniël Lousbergh, Edith Cloes, Lode \\ Beeck, Christel Faes, Liesbeth Bruckers, Raf Mertens, Jan W. Coebergh, \\ Flora E. Leeuwen, et al.
}

\section{To cite this version:}

Patrik Vankrunkelsven, Eliane Kellen, Daniël Lousbergh, Edith Cloes, Lode Beeck, et al.. Reduction in hormone replacement therapy use and declining breast cancer incidence in the Belgian province of Limburg. Breast Cancer Research and Treatment, 2009, 118 (2), pp.425-432. 10.1007/s10549-0090346-9 . hal-00535341

\author{
HAL Id: hal-00535341 \\ https://hal.science/hal-00535341
}

Submitted on 11 Nov 2010

HAL is a multi-disciplinary open access archive for the deposit and dissemination of scientific research documents, whether they are published or not. The documents may come from teaching and research institutions in France or abroad, or from public or private research centers.
L'archive ouverte pluridisciplinaire HAL, est destinée au dépôt et à la diffusion de documents scientifiques de niveau recherche, publiés ou non, émanant des établissements d'enseignement et de recherche français ou étrangers, des laboratoires publics ou privés. 


\title{
Reduction in hormone replacement therapy use and declining breast cancer incidence in the Belgian province of Limburg
}

\author{
Patrik Vankrunkelsven · Eliane Kellen · Daniël Lousbergh · Edith Cloes · \\ Lode Op de Beeck · Christel Faes · Liesbeth Bruckers · Raf Mertens • \\ Jan W. Coebergh · Flora E. Van Leeuwen · Frank Buntinx
}

Received: 7 February 2009/Accepted: 10 February 2009/Published online: 24 February 2009

(C) Springer Science+Business Media, LLC. 2009

\begin{abstract}
Breast cancer is the most common female cancer in Europe, but its incidence and mortality are rapidly changing across Europe. The early termination of the women's health initiative (WHI) trial, after the detection of an increased breast cancer risk in hormone replacement therapy (HRT) users, was followed by strong declines of HRT use worldwide. We investigated whether the reduction of HRT sales affected breast cancer incidence in the Belgian province Limburg. All women registered in the Limburg Cancer Registry with a diagnosis of invasive breast cancer diagnosed between 1/1/1996 and 31/12/2005
\end{abstract}

P. Vankrunkelsven $(\bowtie) \cdot$ E. Kellen · F. Buntinx

Department of General Practice, Katholieke Universiteit Leuven,

Leuven, Belgium

e-mail: patrik@vankrunkelsven.be

D. Lousbergh · E. Cloes

Comprehensive Cancer Institute Limburg, Universiteit Hasselt,

Hasselt, Belgium

L. Op de Beeck

Department of Pathology, Mania hospital, Overpelt, Hasselt, Belgium

C. Faes · L. Bruckers

Interuniversity Institute for Biostatistics and Statistical

Bioinformatics, Universiteit Hasselt, Hasselt, Belgium

R. Mertens

Intermutalistisch Agentschap, Brussel, Belgium

J. W. Coebergh

Comprehensive Cancer Center South, Erasmus University,

Rotterdam, The Netherlands

F. E. Van Leeuwen

Netherlands Cancer Institute, Amsterdam, The Netherlands were included in the study. Data on the use of HRT in the population were obtained from the vendors and the social security system. For age-standardization using the direct method, the European standard population was taken. In 2003 and 2004, the breast cancer incidence rate decreased significantly as compared to 2002 for women aged between 50 and 69 years. This sudden drop in the incidence intercepted a markedly increasing trend until 2002, but was followed again by an increase in 2005. Between 2002 and 2006, the sales of HRT (about $75 \%$ to women aged 50 69 years) were reduced by $41 \%$. Breast cancer incidence was maximally related to HRT use in the previous year $\left(R^{2}=77 \%\right)$. The decrease of breast cancer incidence in the Belgian province of Limburg may largely be related to the fall of HRT use following the early termination of the WHI trial. This suggests that HRT stimulates the growth of preexisting, clinically latent tumours that may not otherwise become clinically apparent.

Keywords Breast cancer - Hormonal therapy ·

Time trends · Epidemiology

\section{Introduction}

Breast cancer is the most common female cancer in Europe, accounting for $29 \%$ of all cancer cases in women. Incidence is generally moving upwards and mortality downwards $[1,2]$. Despite the introduction of organized mammography screening, it remains the leading cause of death from cancer in women [3]. Most breast cancer risk factors are related to a woman's lifetime exposure to estrogens and progestagens: early menarche, late menopause and postmenopausal exogenous hormones increase the risk; while events that decrease the number of 
menstrual cycles, such as late menarche, multiparity and early menopause, reduce the risk [4]. Lactation and early first birth protects against breast cancer. Alcohol use increases the risk. Body fatness is a risk factor for postmenopausal breast cancer; while it protects against premenopausal cancer. Physical activity protects mainly against postmenopausal cancer [5].

The positive relationship between breast cancer and hormone replacement therapy (HRT) has been extensively summarized in a collaborative reanalysis of 51 epidemiological studies: breast cancer risk is increased in women using HRT and increases with longer durations of use; the excess risk drops after cessation and disappears largely after 5 years [6]. In July 2002, the results of the women's health initiative (WHI) randomized trial confirmed that combined estrogen- progestin use was positively associated with increased breast cancer risk [7]. The early termination of the WHI trial received mass media attention and was followed by strong declines of HRT use in the western world [8]. One year later, the Million Women Study, a cohort study of British women, demonstrated that past users did no longer have an increased risk of breast cancer occurrence [9].

The first report linking the reduction of use of HRT to changes in breast cancer incidence described a 1-year 6.7\% decrease in the overall incidence of invasive breast cancer in the United States in 2003 [10].

In the 1990s more than $25 \%$ of postmenopausal women in Belgium used HRT as in the USA [11]. In this study, we investigated whether the reduction of HRT use, following the publication of the preliminary results of the WHI trial, affected breast cancer incidence in the Belgian province of Limburg [12].

\section{Methods}

\section{The Limburg cancer registry}

The province of Limburg (total female population: 408,134 on 31/12/2005) is situated in the north-eastern part of Belgium [13]. The Limburg Cancer registry (LIKAR) was founded in 1993. Its major objective is to follow the incidence and trends of histologically or cytologically confirmed cancers of all inhabitants of Limburg and to continuously analyse the collected data. These data are provided by all the pathological, cytological and hematological laboratories located in the province and by some laboratories outside the province which more than occasionally examine samples from Limburg inhabitants [14]. In the analysis, all women with a diagnosis of invasive breast cancer diagnosed between 1/1/1996 and 31/12/2005 are included Table 1.
Table 1 Absolute number of mamma carcinomas in the province of Limburg from 1996 to 2005

\begin{tabular}{rlrlll}
\hline & -40 year & $40-49$ year & $50-69$ year & +70 year & Total \\
\hline 1996 & 35 & 80 & 179 & 94 & 388 \\
1997 & 27 & 78 & 186 & 87 & 378 \\
1998 & 31 & 97 & 197 & 89 & 414 \\
1999 & 33 & 111 & 223 & 121 & 488 \\
2000 & 30 & 111 & 238 & 100 & 479 \\
2001 & 31 & 105 & 287 & 129 & 552 \\
2002 & 37 & 96 & 340 & 133 & 606 \\
2003 & 29 & 110 & 289 & 145 & 573 \\
2004 & 31 & 98 & 278 & 130 & 537 \\
2005 & 37 & 107 & 324 & 174 & 642 \\
\hline
\end{tabular}

Use of hormone replacement therapy in Belgium

Data on drug use and sales are only available on a national level. We assume, however, that trends of HRT use in the province of Limburg do not substantially differ from the trend in the entire country of Belgium.

Data were obtained from two different databases. Firstly, information was collected on the sales of the following HRT preparations in Belgium between 1992 and 2006 (orally or transdermally administered drugs): combinations of estrogen and progestin (in one vehicle or separately), estrogen only, and tibolone [15]. Tibolone is a synthetic steroid that possesses weak estrogenic, progestational and androgenic properties [16].

Secondly, for the period 2002-2005 information was obtained from the 'Intermutualistisch Agentschap' (IMA), which collects data of all Belgian Health Insurance companies. For a random sample of the Belgian population (stratified by age, sex and residence), the prescribed and reimbursed medication per person is registered. The sample covers $2.5 \%$ of the national population. The IMA data were used to study the age distribution of women taking HRT and used as a check for the data collection based on sales of HRT preparations. By restricting the analysis to women taking at least 55 DDDs HRT per semester, occasional users were excluded.

A list of the preparations included in the analysis is provided in the Appendix.

\section{Statistical analysis}

The population at risk was calculated as the average of the population at the beginning and the end of each year. Agespecific incidence rates were expressed per 100,000 women per year. European standardised incidence rates (ESR) were calculated by applying the observed age-specific rates directly to the European standard population [14, 17]. 
Sales of drugs are recorded as units delivered to patients; data covering 1 year were redefined to 'defined daily doses' (DDD) and divided by 365 to obtain 'a yearly dose'. The number of yearly doses estimates the number of women taking HRT.

To know the total amount of women who are taking a combination of estrogen and progestin we had to calculate the amount of separately sold estrogen that was opposed by progestin. The latter was calculated by assuming that the fall in sales of progestin between 2001 and 2006 is largely due to the reduction in sales of progestin that opposes estrogen. The following formula represents the decrease of estrogen: $Z=$ (DDD of estrogen in 2006)-(DDD of estrogen in 2001). The change in sales of progestin, calculated in the same manner, was named $Y$. The percentage of (separately sold) estrogen that is opposed by progestin was calculated as $(Y / Z) \times 100$ and equalled $54.1 \%$.

In Belgium, the reimbursed HRT preparations represent on average $57 \%$ of all sold drugs used as HRT. As reimbursed and not reimbursed medication disperse equally in the population, the percentage of women using reimbursed HRT per age group was multiplied with 1.8 to correspond with the total HRT consumption.

Breast cancer incidence in women between 50 and 69 years was related to the HRT use in the years of diagnosis as well as in the years before, using linear regression analyses in order to study the time frame in which HRT use maximally predicted breast cancer incidence.

The evolution over time of the probability of having breast cancer was investigated by means of a breakpoint analysis. In this analysis the logit of the probability of having breast cancer is described by three straight lines. One for the period 1996-2002, one for the period 20022004 and finally one for the period 2004-2005.

\section{Results}

Time trends in invasive breast cancer incidence rates in the Province Limburg

During the period 1997-2002, age-standardized invasive breast cancer incidence increased steadily: ESR raised from 96 to 139 per 100,000 women ( $+45 \%$ in total or $9 \%$ yearly) [14]. However, in 2003 the incidence rate decreased sharply (ESR: 125/100,000) and this reduction continued in 2004 (ESR: $113 / 100,000)(-9.5 \%$ yearly). This reduction was followed by an increase in 2005, the last year for which data are available (ESR: 130/100,000) $(+15 \%)$.

The evolution of the incidence rates differed for the different age-groups. For women below the age of 50 no significant trend change in incidence rates was noted in the period 1996-2005.
For women aged between 50 and 69 a break point analyses was performed to investigate whether or not the increase and decrease are significant from a statistical point of view. The breakpoints were fixed in 2002 and 2004. The model describes the probability that a woman, aged 50-69, gets breast cancer. Between 1996 and 2002, this probability rose significantly. Every year, the odds increased by 1.09 $(P<0.0001)$. Between 2002 and 2004 the probability declined. The odds decreased every year by 0.98 $(P=0.0040)$. The last period, between 2004 and 2005 is too short to be decisive: the probability increases not significantly $(P=0.076)$.

For women aged 70 years and above the incidence rate in this 10 year period rose more steadily (Fig. 1).

Furthermore, for women aged between 50 and 69 years, the evolution of the incidence of invasive lobular carcinoma was more marked than the one of invasive ductal carcinoma. Invasive lobular carcinoma rose between 1996 and 2002 from 20 to 59 cases per 100,000 $(+200 \%$; $\mathrm{RR}=3.00$ (95\% CI 1.73-5.22; $P<0.001))$ and fell to 31 cases per 100,000 in $2004(-47 \%$; RR $=0.53(95 \% \mathrm{CI}$ $0.34-0.83 ; P<0.01)$ ); invasive ductal carcinoma, respectively, rose from 139 to 275 ( $+98 \%$; RR $=1.98(95 \%$ CI $1.59-2.47 ; P<0.001))$ and fell to $224(-19 \% ; \mathrm{RR}=0.81$ (95\% CI $0.68-0.98 ; P<0.03)$ ). The increases in 2005 of both groups were not significant (Fig. 2).

\section{Evolution of the use of HRT in Belgium}

In 1992 173,612 yearly HRT doses were sold, of which $27 \%$ as fixed estrogen-progestin, $35 \%$ as opposed estrogen and $38 \%$ as unopposed estrogen. In 2001, sales peaked to 349,879 yearly doses of which $43 \%$ as estrogen-progestin,

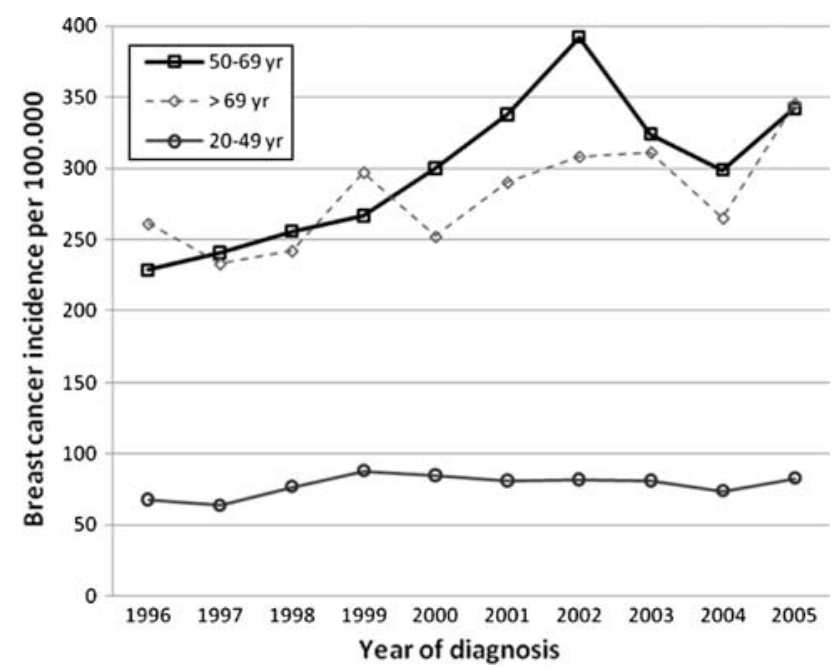

Fig. 1 Invasive breast cancer incidence rates among women in Limburg according to age and year of diagnosis, 1996-2005 


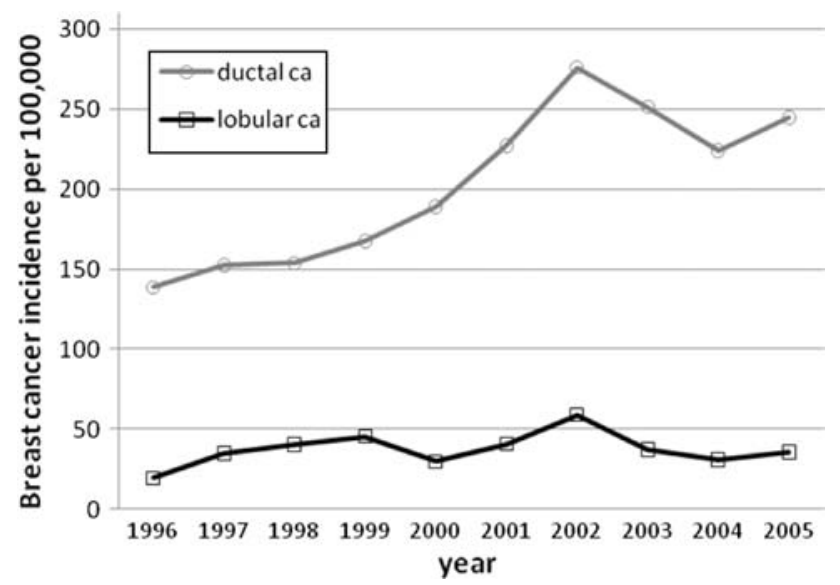

Fig. 2 Annual incidence rates for invasive breast cancer in Limburg 1996-2005 by histological status, the raise and fall of invasive lobular carcinoma is relativity stronger than the one of invasive ductal carcinoma

$22 \%$ as opposed estrogen, $24 \%$ as unopposed estrogen and $11 \%$ as tibolone. This was followed by a drop in the use of HRT. In 2005 sales were reduced by $41 \%$ to 203,970 yearly doses (of which $39 \%$ as estrogen-progestin, $21 \%$ as opposed estrogen, $23 \%$ as unopposed estrogen and $17 \%$ as tibolone) (Fig. 3).

We examined the yearly sales of the different HRT preparations in detail. The sales of the opposed estrogen

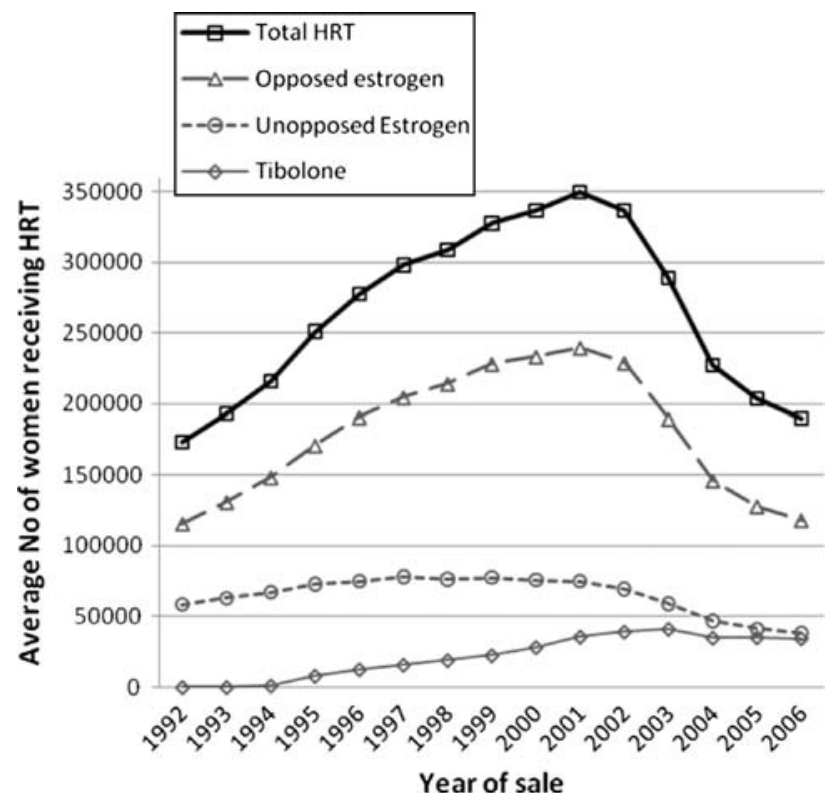

Fig. 3 Yearly sales of HRT. The curves indicate the average number of women receiving HRT per year, based on the sales of defined daily doses of HRT divided by 365 days. Opposed estrogen is the sum of drugs sold as a fixed combination of estrogen and progestin and on the other hand estrogen that is sold separately but that is opposed with separately sold progestin and estrogen-progestin combinations evolved similarly. Between 2002 and 2006, the sales were reduced to $50 \%$. However, the trends in tibolone sales differed: it rose until 2003, fell in 2004 with $15 \%$ and then stabilized.

In $20029.8 \%$ of women aged 45-49 years used HRT; while this proportion was $27 \%$ and $9.2 \%$ in the women aged 50-69 years and 70-74 years. As discussed above, in 2005, HRT use was significantly lower (5.3, 12 and 5.3\% for the different age-groups, respectively) (Fig. 4). More than $75 \%$ of all hormones were bought by women aged 50-69 years.

Relation between trends in HRT use and trends in breast cancer incidence

Since the start of the registration of breast cancer incidence in Limburg (1996 up to 2004), the change in breast cancer incidence in women aged 50-69 years followed a time course that is similar to the use of HRT. A linear regression model was used to relate the breast cancer incidence in women aged 50-69 years to the HRT sales. It turned out that the HRT sales in the year before explained the incidence best. The relationship can be described by the following expression:

$$
\begin{aligned}
\text { Incidence in year }(x)= & -142.5+0.00141 \\
& \times \text { HRT sales in year }(x-1) .
\end{aligned}
$$

The HRT sales in year $(x-1)$ explains $78 \%$ of the variability of the incidence in year $x(P=0.002)$. However, sales of HRT lost significance in explaining the breast cancer incidence, if the data of 2005 were added (Fig. 5).

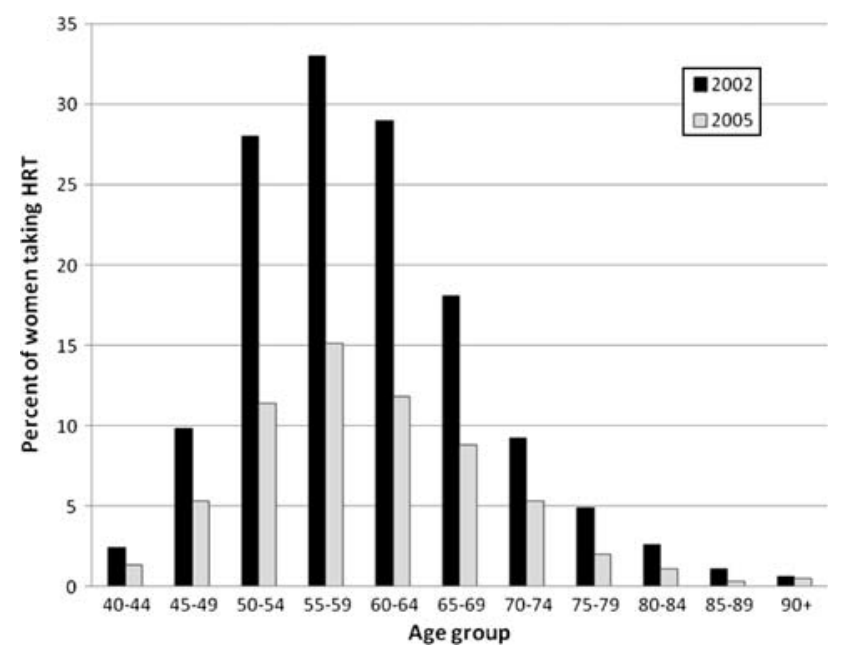

Fig. 4 Percentage of women taking hormonal replacement therapy (HRT) in the first half of 2002 and the second half of 2005 according to age group based on data of insurance companies who registered women who bought $>55$ DDD of HRT per half a year 
Fig. 5 The upper curve indicates the average number of women receiving HRT per year, based on the sales of defined daily doses of HRT divided by 365 days, from 1992 to 2005.

The other curve indicates the cancer incidence rate among women in Limburg aged 50-69 year at diagnosis from 1996 to 2005

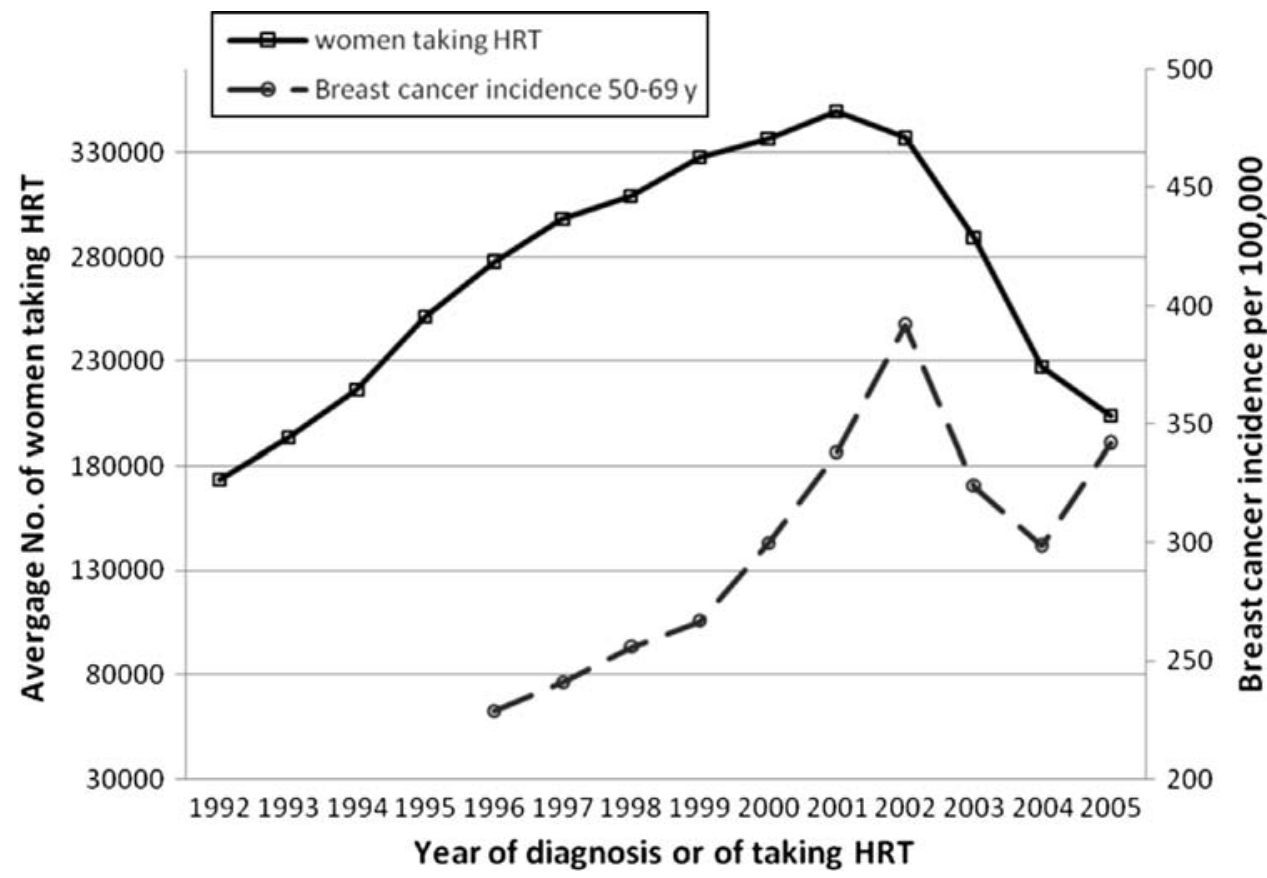

have changed over the past 10 years, it was not nearly as important as the reduction of HRT.

As screening mammography influences breast cancer incidence we studied variation of screening during the study period. The start of a screening programme leads to an increase in incidence rates, as both prevalent (the so called 'prevalence pool') and incident cases are being diagnosed. But when the penetration of a screening programme reaches a plateau and the pool of prevalent cases decreases, incidence rates drop [23]. Up to 2000 biennial mammographic breast cancer screening for women aged 50-69 years was not well organised in Belgium: municipalities, provinces, the Flemish and Belgian government launched most of the time independently programmes to make women and physicians more aware about the importance of mammography. These actions resulted to the following proportions of screened women (aged 5069 years): $38 \%$ in 1990-1991; 46\% in 95-96 [24]. The rate stabilized on the latter percentage until 2000-2001. A more accurate screening programme of the Flemish government was established in 2000 and did rise the proportion of screened women to $58 \%$ in $2002-2003$ and $64 \%$ in 2004 2005 [25]. The screened population was consequently stable in the years before and the first 6 years of our registration period. However, the screening saturation in this period did not cause a drop of incidence rate as could be expected. Between 2002 and 2005 the screening rate increased slightly and should have created a rise of the incidence of breast cancer in this period, our results however, showed the opposite as the registered breast cancers in Limburg dropped in 2003-2004 and in 2005 they believe that although the incidences of other factors such as obesity or health awareness behaviour may 
approximated the rate of 2001. The interference of screening mammography consequently could have diminished the influence of the rising and declining HRT use on breast cancer incidence and it could be responsible for the increased incidence in 2005. This results endorse other observations indicating that HRT use is a more important factor than screening as an explanation for the rise and drop of breast cancer [26].

Furthermore, HRT use affects mammographic screening in two ways. Firstly, women who take HRT have access to health care, thus have a greater likelihood of being treated for co-morbidity or being motivated to undergo mammographic screening [27]. However, in the province of Limburg, the reduction in HRT use was not followed by a decrease in mammographic screening, in contrary the screening rose in that period. Secondly, estrogen and progestin use is associated with an increase in breast density leading to a reduction in sensitivity and specificity of the mammography; thus cessation of HRT use may lead to the detection of some tumours which were invisible before and thus to a short term increase in incidence [28]. Saturation of screening may partly be responsible for the observed decline in breast cancer incidence.

Use of HRT seems to be associated with a high risk of tubular and lobular invasive carcinomas, which are typically small, low grade and hormone receptor positive [9]. In contrast, the association with invasive ductal carcinomas is lower [29]. Our results endorse this relative susceptibility: the decline in invasive lobular carcinoma was larger than of invasive ductal carcinoma. Recent analyses on 13 US regional cancer registries found inverse results, leading the authors to hypothesize that saturation in screening was primarily responsible for the decline in rates seen in the US [30]. In that study the in situ tumour rates also remained constant [30]. However, in the Limburg Cancer Registry the incidence of non-invasive breast tumours carefully followed the pattern of the invasive tumours (data not shown), as in global population in the US [31]. Our results plead more for a hormonal effect caused by HRT use.

The association between changes in HRT use and changes in breast cancer incidence is biologically plausible. It may be that HRT promotes growth of pre-existing, clinically latent, hormone-dependent cancers of low malignant potential, that may not otherwise become clinically apparent [32]. This suggests that exogenous hormones stimulate growth of occult tumours rather than act as initiators of carcinogenesis [33]. Biologically, it seems indeed that exogenous hormones do not induce malignant tumours de novo, but accelerates the growth of already existing tumour cells [34]. In another study the decrease in proliferation was limited to ER-positive, but not ER-negative tumours upon withdrawal of HRT, and this within a month after stopping [35]. The increase in breast cancer incidence in 2005 may be consistent with the hypothesis that changes in the hormonal environment temporarily slowed the growth of tumours instead of a more profound effect on breast cancer occurrence [10]. A longer follow up of the incidence of breast cancer must help to fully understand the biological mechanism [36].

Over the registration period, no changes were made in the procedures of cancer registration, nor in the collection and analyzing of the data. No other drugs besides HRT showed substantial changes in sales during the period 2002-2005. The sales of selective estrogen receptor modulators started in 2000 and reached $4 \%$ of the total HRT sales in 2002, but stabilized at $5 \%$ during the following years.

In interpreting our results, some limitations need to be considered. Our study had a descriptive, ecological design and was not based on individual data on the use of HRT, mammography screening and breast cancer. Ecological studies can most often not demonstrate a causal association, but merely suggest hypotheses for further investigation. Ecologic fallacy arises when we ascribe to a group of women characteristics (such as prevalence of HRT use) that they may in fact not have as individuals. However, the changes are strong and statistical significant, even for the decreasing leg of the incidence curve only lasting for 2 years. Although the cancer registry makes considerable efforts to contact the laboratories examining biopsies from inhabitants of Limburg, some underreporting may exist. The risk of breast cancer among HRT users seems to be greater for early-stage, small, low-grade, ERpositive tumours than for tumours with a higher stage and grade [32]. Unfortunately, we were not able to confine the analyses to stage or to hormone positive tumours as LIKAR does not register tumour size and stage at diagnosis or if the tumour is hormone positive.

In conclusion, we found that the recent decrease of breast cancer incidence in the Belgian province of Limburg seems strongly related to the previous and concurrent fall of HRT use following the early termination of the WHI trial. HRT stimulates the growth of pre-existing clinically latent tumours with low malignant potential but can also accelerate the growth of already existing tumours.

Acknowledgments This research project was financially supported by the Foundation against Cancer, Belgium. The Limburg Cancer Registry is funded by the Flemish Ministry of Health and the Province of Limburg.

\section{Appendix}

See Table 2. 
Table 2 List of the preparations included in the analysis

\begin{tabular}{|c|c|}
\hline Preparation & Manner of administration \\
\hline \multicolumn{2}{|l|}{ Estrogen-progestin combinations } \\
\hline Estradiol/norethisterone acetate & Oral*/transdermal \\
\hline Estradiol/dydrogesterone & Oral \\
\hline Estradiol valerate/diënogest & Oral \\
\hline $\begin{array}{l}\text { Estradiol valerate/cyproterone } \\
\text { acetate }\end{array}$ & Oral \\
\hline Estradiol valerate/norgestrel & Oral* \\
\hline $\begin{array}{l}\text { Estradiol valerate/ } \\
\text { medroxyprogesterone acetate }\end{array}$ & Oral* \\
\hline Estradiol hemihydrate/levonorgestrel & Transdermal \\
\hline $\begin{array}{l}\text { Conjugated equine estrogen/ } \\
\text { medroxyprogesterone }\end{array}$ & Oral \\
\hline Estradiol/trimegestone & Oral \\
\hline \multicolumn{2}{|l|}{ Estrogen only } \\
\hline Estradiol & $\begin{array}{l}\text { Oral/transdermal/ } \\
\text { transnasal/implant }\end{array}$ \\
\hline Estradiol valerate & Oral* \\
\hline Estradiol benzoate & Intramuscular \\
\hline Estradiol fenylpropriate & Intramuscular \\
\hline Conjugated equine estrogen & Oral* \\
\hline \multicolumn{2}{|l|}{ Progestin only } \\
\hline Progesterone & Oral/transdermal \\
\hline Dydrogesterone & Oral \\
\hline Medroxyprogesterone acetate & Oral \\
\hline Nomegestrol acetate & Oral \\
\hline Lynestrenol & Oral \\
\hline Norethisterone acetate & Oral \\
\hline Medrogestone & Oral \\
\hline Tibolone & Oral \\
\hline
\end{tabular}

* Reimbursed medication

\section{References}

1. Karim-Kos HE, de Vries E, Soerjomataram I, Lemmens V, Siesling S, Coebergh JW (2008) Recent trends of cancer in Europe: a combined approach of incidence, survival and mortality for 17 cancer sites since the 1990s. Eur J Cancer 44(10):1345-1389. doi: 10.1016/j.ejca.2007.12.015

2. Héry C, Ferlay J, Boniol M, Autier P (2008) Changes in breast cancer incidence and mortality in middle-aged and elderly women in 28 countries with Caucasian majority populations. Ann Oncol 19(5):1009-1018. doi:10.1093/annonc/mdm593

3. Ferlay J, Autier P, Boniol M, Heanue M, Colombet M, Boyle P (2007) Estimates of the cancer incidence and mortality in Europe in 2006. Ann Oncol 18(3):581-592. doi:10.1093/annonc/mdl498

4. Key TJ, Verkasalo PK, Banks E (2001) Epidemiology of breast cancer. Lancet Oncol 2(3):133-140. doi:10.1016/S1470-2045 (00)00254-0

5. World Cancer Research Fund/American Institute for Cancer Research (2007) Food, nutrition, physical activity, and the prevention of cancer: a global perspective. AICR, Washington DC

6. Collaborative Group on Hormonal Factors in Breast Cancer (1997) Breast cancer and hormone replacement therapy: collaborative reanalysis of data from 51 epidemiological studies of 52,705 women with breast cancer and 108,411 women without breast cancer. Lancet 350(9084):1047-1059. doi:10.1016/S01406736(97)08233-0

7. Rossouw JE, Anderson GL, Prentice RL, LaCroix AZ, Kooperberg C, Stefanick ML et al (2002) Risks and benefits of estrogen plus progestin in healthy postmenopausal women: principal results from the Women's Health Initiative randomized controlled trial. JAMA 288(3):321-333. doi:10.1001/ jama.288.3.321

8. Majumdar SR, Almasi EA, Stafford RS (2004) Promotion and prescribing of hormone therapy after report of harm by the Women's Health Initiative. JAMA 292(16):1983-1988. doi: 10.1001/jama.292.16.1983

9. Beral V (2003) Breast cancer and hormone-replacement therapy in the Million Women Study. Lancet 362(9382):419-427. doi: 10.1016/S0140-6736(03)14065-2

10. Ravdin PM, Cronin KA, Howlader N, Berg CD, Chlebowski RT, Feuer EJ et al (2007) The decrease in breast-cancer incidence in 2003 in the United States. N Engl J Med 356(16):1670-1674. doi: 10.1056/NEJMsr070105

11. Lundberg V, Tolonen H, Stegmayr B, Kuulasmaa K, Asplund K (2004) Use of oral contraceptives and hormone replacement therapy in the WHO MONICA project. Maturitas 48(1):39-49. doi:10.1016/j.maturitas.2003.08.006

12. Soerjomataram I, Coebergh JW, Louwman MW, Visser O, van Leeuwen FE (2007) Does the decrease in hormone replacement therapy also affect breast cancer risk in the Netherlands? J Clin Oncol 25(31):5038-5039. doi:10.1200/JCO.2007.13.7281

13. National Institute for Statistics Bevolkingsdata (2008) http:// ecodata.mineco.fgov.be/. Ministry of Economics, Vooruitgangsstraat 50 , Brussel

14. Lousbergh D, Cloes E, Op De Beeck L, Rummens JL, Vandenbrande J, Faes C, Bruckers L, Molenberghs G, Dhollander D, Kellen E, Hensen K, Lathouwers D, Meekers E, Buntinx F (2007) Ten years of cancer in the Belgian Province of Limburg: 19962005. LIKAR, Hasselt

15. IMS Health Belgium, Rue de Crayer 6, 1000 Brussels (2008) Drug sales in Belgium per three months

16. Albertazzi P, Di Micco R, Zanardi E (1998) Tibolone: a review. Maturitas 30(3):295-305. doi:10.1016/S0378-5122(98)00059-0

17. dos Santos Silva I (1999) Cancer epidemiology: principles and methods. IARC, Lyon

18. Katalinic A, Rawal R (2008) Decline in breast cancer incidence after decrease in utilisation of hormone replacement therapy. Breast Cancer Res Treat 107(3):427-430. doi:10.1007/s10549007-9566-Z

19. Verkooijen HM, Koot VC, Fioretta G, van der Heiden M, Schipper ME, Rapiti E et al (2008) Hormone replacement therapy, mammography screening and changing age-specific incidence rates of breast cancer: an ecological study comparing two European populations. Breast Cancer Res Treat 107(3):389395. doi:10.1007/s10549-007-9554-3

20. Van Duijnhoven FJ, van Gils CH, Bezemer ID, Peeters PH, van der Schouw YT, Grobbee DE (2006) Use of hormones in the menopausal transition period in the Netherlands between 1993 and 1997. Maturitas 53(4):462-475. doi:10.1016/j.maturitas. 2005.08.002

21. Zahl PH, Maehlen J (2007) A decline in breast-cancer incidence. N Engl J Med 357(5):510-511

22. Botha JL, Bray F, Sankila R, Parkin DM (2003) Breast cancer incidence and mortality trends in 16 European countries. Eur J Cancer 39(12):1718-1729

23. Jemal A, Ward E, Thun MJ (2007) Recent trends in breast cancer incidence rates by age and tumor characteristics among US women. Breast Cancer Res 9(3):R28. doi:10.1186/bcr1672 
24. VRIND Statistisch Jaarrapporten Vlaamse regering (1998-2000) http://aps.vlaanderen.be/statistiek/publicaties/stat_Publicaties_ vrind.htm

25. Intermutualistisch Agentschap. Programma borstkankerscreening (2008) Periodes van 2002-2003 en 2004-2005. www.nic-ima.be

26. Kumle M (2008) Declining breast cancer incidence and decreased HRT use. Lancet 372(9639):608-610. doi:10.1016/S0140-6736 (08)61255-6

27. Nelson HD, Humphrey LL, Nygren P, Teutsch SM, Allan JD (2002) Postmenopausal hormone replacement therapy: scientific review. JAMA 288(7):872-881. doi:10.1001/jama.288.7.872

28. Kerlikowske K, Miglioretti DL, Buist DS, Walker R, Carney PA (2007) Declines in invasive breast cancer and use of postmenopausal hormone therapy in a screening mammography population. J Natl Cancer Inst 99(17):1335-1339. doi:10.1093/ jnci/djm111

29. Reeves GK, Beral V, Green J, Gathani T, Bull D (2006) Hormonal therapy for menopause and breast-cancer risk by histological type: a cohort study and meta-analysis. Lancet Oncol 7(11):910-918. doi:10.1016/S1470-2045(06)70911-1

30. Li CI, Daling JR (2007) Changes in breast cancer incidence rates in the United States by histologic subtype and race/ethnicity, 1995 to 2004. Cancer Epidemiol Biomarkers Prev 16(12):27732780. doi:10.1158/1055-9965.EPI-07-0546

31. Centers for Disease Control and Prevention (2007) Decline in breast cancer incidence-United States 1999-2003. MMWR $56: 549-553$
32. Kerlikowske K, Miglioretti DL, Ballard-Barbash R, Weaver DL, Buist DS, Barlow WE et al (2003) Prognostic characteristics of breast cancer among postmenopausal hormone users in a screened population. J Clin Oncol 21(23):4314-4321. doi: 10.1200/JCO.2003.05.151

33. Garcia-Closas M, Sherman ME, Brinton LA (2006) Clarifying breast cancer risks associated with menopausal hormone therapy. Lancet Oncol 7(11):885-886. doi:10.1016/S1470-2045(06) 70915-9

34. Dietel M, Lewis MA, Shapiro S (2005) Hormone replacement therapy: pathobiological aspects of hormone-sensitive cancers in women relevant to epidemiological studies on HRT: a minireview. Hum Reprod 20(8):2052-2060. doi:10.1093/humrep/ dei043

35. Prasad R, Boland GP, Cramer A, Anderson E, Knox WF, Bundred NJ (2003) Short-term biologic response to withdrawal of hormone replacement therapy in patients with invasive breast carcinoma. Cancer 98(12):2539-2546. doi:10.1002/cncr.11836

36. Early Breast Cancer Trialist's Collaborative Group (EBCTCG) (2005) Effects of chemotherapy and hormonal therapy for early breast cancer on recurrence and 15-year survival: an overview of the randomised trials. Lancet 365(9472):1687-1717. doi:10.1016/ S0140-6736(05)66544-0 